\title{
A Study on Parameters Influencing Blast-Induced Frequency Content and Dominant Frequency Attenuation
}

\author{
Milad Aftabi (iD, Mohammad hossein Motamedi, and Hamed Molladavoodi \\ Department of Mining Engineering, Amirkabir University of Technology, Tehran, Iran \\ Correspondence should be addressed to Milad Aftabi; miladaftab97@aut.ac.ir
}

Received 26 September 2021; Revised 21 January 2022; Accepted 8 February 2022; Published 3 March 2022

Academic Editor: Zhaoye Qin

Copyright (C) 2022 Milad Aftabi et al. This is an open access article distributed under the Creative Commons Attribution License, which permits unrestricted use, distribution, and reproduction in any medium, provided the original work is properly cited.

\begin{abstract}
Adverse effects of the blasting vibration on surrounding structures intensify importance of investigation on the blast frequency content while it has not been fully considered in blasting design. In this study, blast-induced frequency content and dominant frequency attenuation are investigated. The results of this study and its comparison with the previous studies demonstrate that investigation of different parameters influencing blast-induced frequency content including peak blast load pressure, rise time, and falling time by the experimental pressure-time history with its Fast Fourier Transform (FFT) analysis leads to the similar results of study by the velocity-time recorded data of an infield blasting. The outcomes of this study on dominant frequency attenuation for different types of explosives but in the same material show approximately the same dominant vibration frequency in far-field for different explosives, whereas a rapid drop of dominant frequency to half of the initial value in near distance to the blasthole can be observed. Investigation on dominant frequency attenuation versus distance for the materials with different natural ground frequencies demonstrates that the geomaterial tends to pass the vibration frequency closer to its natural frequency. If the earth has a lower natural frequency, it will pass the waves with lower dominant frequencies, but it will attenuate the waves with higher dominant frequency.
\end{abstract}

\section{Introduction}

Drilling and blasting is an affordable and flexible method for rock mass excavation in different geological conditions [1]. Sufficient rock fragmentation and minimum damage and vibration are the main goals of blasting for different purposes such as open-pit and underground mines and surficial structures damage $[1,2]$.

Rock fragmentation is considerably affected by the shock wave because of its supersonic speed [3]. According to Kutter and Fairhurst suggestion, three distinct zones are formed surrounding a blasthole named (1) a crushed zone due to strong hydrodynamic shock, (2) a transitional, nonlinear (cracked) zone, and (3) an elastic zone (Vibration Zone). The parameters of blast-induced vibration, i.e., peak particle velocity (PPV), vibration frequency, and duration, can adversely affect the nearby structures such as buildings, tunnels, bridges, and dams which are the major concerns for designers and constructors in mining industry and construction operations $[3,4]$. The vibration may be amplified and causes damage to the structures because the resonance occurs due to approximate equivalence between the natural frequency of the structures and dominant frequency of the vibration. Nowadays, frequency-based control has been adopted by the US Office of Surface Mining and many members of the European Union. With developments in blasting safety control, many studies demonstrate that the vibration frequency is an important index to improve the accuracy of assessing blast-induced damage [4-6]. To minimize blast-induced structural damage, much research has been performed to study the frequency content of blasting and its effects on surrounding structures $[3,7-10]$. Thanks to numerical simulation, studies about the complicated mechanical and dynamical behavior of intact and jointed rock masses have been promoted recently [11-15]. There are several restrictions in experimental studies and their results interpretation because of high costs and difficulties in providing controlled conditions. Therefore, 
numerical modeling can be an opportunity to study the mechanisms of explosion and its side effects and raise our knowledge of the blasting process considering the response of rock materials to dynamic loads $[16,17]$. This paper is divided into two sections: firstly, the analysis of different parameters influencing blast-induced frequency content, including peak blast load pressure, rise time, and falling time, based upon the Fourier transform of the blasting pressure-time history functions using MATLAB software; secondly, the study of dominant frequency attenuation for the materials with different natural frequencies and different types of explosives in Sangan iron ore mine (Iran) using numerical simulation in FLAC environment.

\section{Pressure-Time History Functions of Blasting}

Numerical simulation is an important method to study the explosion mechanism. Implementation of the pressure-time history function imposed at the surrounding wall of the blasting hole is one of the widely used approaches to model the blasting loading. Empirical equations based on detonation theories are extensively used to estimate the pressuretime history function applied in blasting hole walls since it is difficult to experimentally measure it [18]. Table 1 presents some important blasthole wall pressure-time functions implemented in the literature.

One of the most important components of vibration analysis is the investigation and evaluation of the frequency content of the recorded signals. To do this, the mathematical operation must be performed to transform the signal from the time domain, which expresses the amount of vibration amplitude in time, to the frequency domain, where the amount of vibration amplitude is measured in terms of frequency. The Fast Fourier Transform (FFT) application is a well-known method to analyze the frequency content of a dynamic function. FFT analysis is the least costly and simplest way nowadays that can be utilized to solve resonance and magnification problems successfully in every blast practice. The Fourier transform (FT) of the dynamic blasting function $f(t)$ is the frequency-based function $F(\omega)$, as follows:

$$
F(\omega)=\int_{-\infty}^{\infty} f(t) e^{-i \omega t} \mathrm{~d} t
$$

and the inverse Fourier transform is

$$
f(t)=\int_{-\infty}^{\infty} F(\omega) e^{-i \omega t} \mathrm{~d} \omega,
$$

where $i=\sqrt{-1}$ and $e^{i \theta}=\cos \theta+i \sin \theta$.

If $f(t)$ is considered as input signal (i.e., input data), $F(\omega)$ will be the signal's spectrum.

\section{Influence of Peak Blast Load Pressure, Rise Time, and Falling Time on the Frequency Content}

A Fast Fourier Transform (FFT) algorithm in MATLAB software is used to investigate the influence of different parameters on the frequency content, including peak blast load pressure, rise time, and falling time. The pressure-time
TABLE 1: Some important blasthole wall pressure-time functions.

\begin{tabular}{lc}
\hline Blasthole wall pressure-time function & Proposed by \\
\hline$p=p_{p} e^{-\alpha t}$ & {$[19]$} \\
$P=P_{p}\left(e^{-\alpha t}-e^{\delta t}\right)$ & {$[20]$} \\
$P=P_{p} t^{n} e^{-\alpha t}$ & {$[21]$} \\
$P=P_{p}\left(e^{\left(-t / t_{a}\right)\left(1--t / t_{a}\right)}\right)$ & {$[22]$} \\
$P=4 P_{p}\left(e^{-\beta t / \sqrt{2}}-e^{-\sqrt{2} \beta t}\right) \cdot \beta=-\sqrt{2} \ln (1 / 2) / t_{r}$ & {$[23]$} \\
$P=P_{p}\left(t / t_{r} e^{\left(1--t / t_{r}\right)}\right)$ & {$[24]$} \\
\hline
\end{tabular}

$P_{p}$ is the maximum borehole pressure, $t_{r}$ is rise time, $\alpha$ and $\delta$, and $n$ are constant values, $t$ is the duration time, and $t_{a}$ is the arrival time.

history function proposed by Jiang and Baird [24] in equation (3) is transformed from time to frequency domains using the FFT algorithm.

$$
P_{t}=P_{p}\left(\frac{t}{t_{r}} \exp \left(1-\frac{t}{t_{r}}\right)\right)
$$

where $P_{p}$ is the peak blasthole pressure, $t$ is the elapsed time, and $\operatorname{tr}$ is the rise time.

Furthermore, for validation of this paper, the results are compared with the study by Yang et al. [25] on blast-induced frequency based on velocity-time recorded data. To compare accurately between two different results, the input applied parameters such as the peak blast load pressure, rise time, and falling time are selected the same as what is applied by Yang et al. [25].

3.1. Impact of Peak Blast Load Pressure on the Frequency Content. Three different blasthole pressures equal to 5, 10, and $20 \mathrm{MPa}$ suggested by Yang et al. [25] are taken into account. Furthermore, the falling and rise times are considered equal to 12 and $0.8 \mathrm{~ms}$, respectively.

As it can be seen in Figure 1, the blasthole pressure does not affect the frequency content. The results by Yang et al. [25] also show the same independence of frequency content on peak blast load pressure.

3.2. Impact of Rise Time on the Frequency Content. The different rise times offered by Yang et al. [25] equal to $0.8,1.6$, and $3.2 \mathrm{~ms}$ are selected for FFT analysis of blasting process. However, the blasthole pressure and falling time are also considered constant equal to $5 \mathrm{MPa}$ and $11.2 \mathrm{~ms}$, respectively. Figure 2 illustrates that the dominant frequency is not affected by the different rise times. However, the more rise time leads to less lateral extension of the frequency content and very high frequencies do not generate.

3.3. Impact of Falling Time on the Frequency Content. The falling times offered by Yang et al. [25] equal to 5.6, 11.2, and $22.4 \mathrm{~ms}$ are selected for FFT analysis of the blasting process. The peak blasthole pressure and rise time are considered to be $5 \mathrm{MPa}$ and $0.8 \mathrm{~ms}$, respectively. Figure 3 demonstrates that the increment of falling time leads to a decline in the dominant frequency of blasting. The results of this study are in agreement with Yang et al. [25] results. 


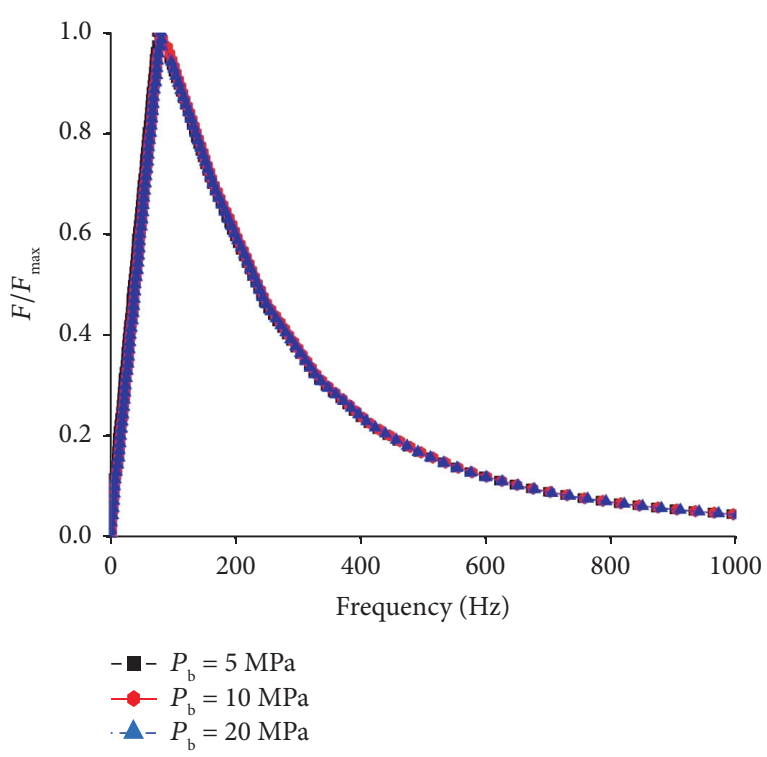

(a)

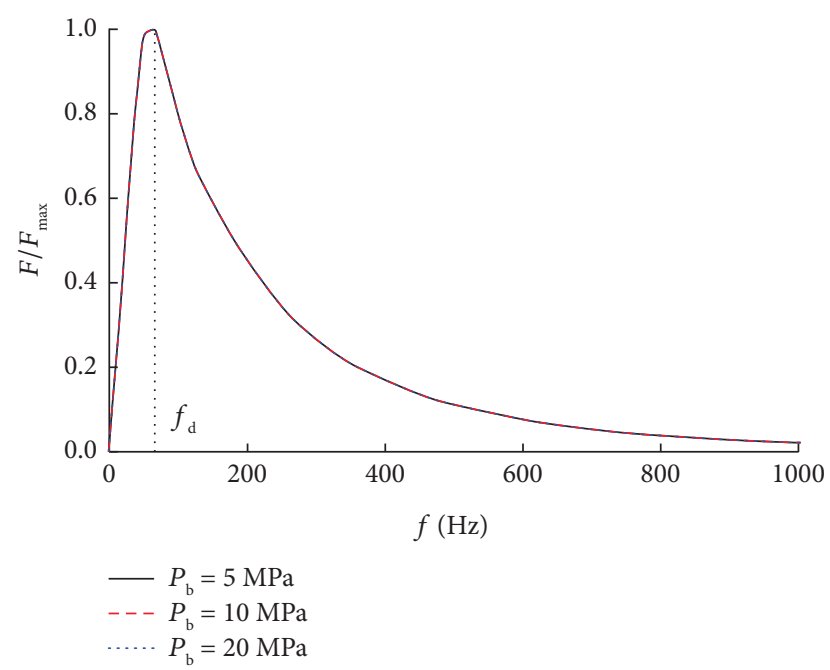

(b)

FIgURE 1: The effect of maximum blasthole pressure on frequency content: (a) this study's results; (b) the results by Yang et al. [25]. fd represents the dominant frequency.

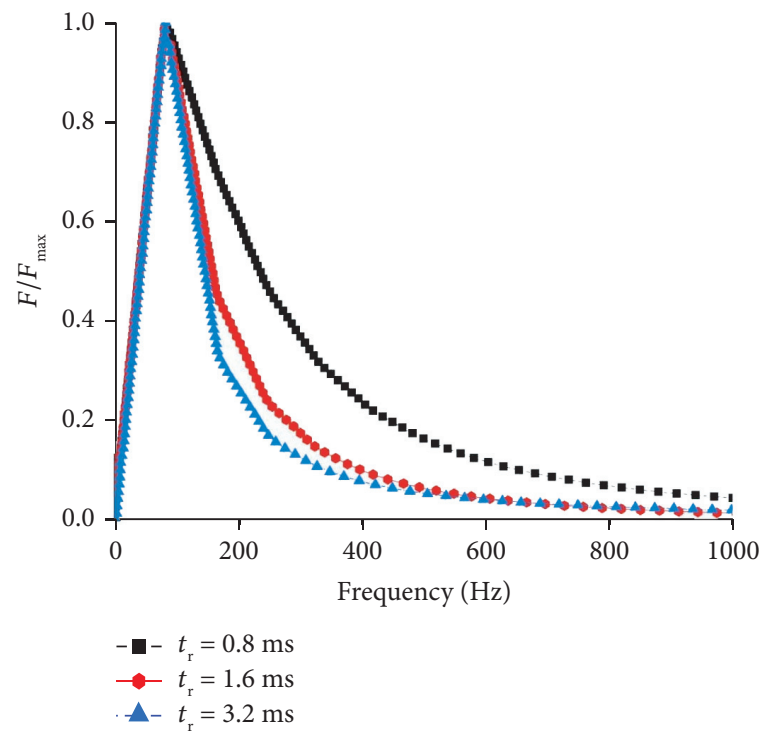

(a)

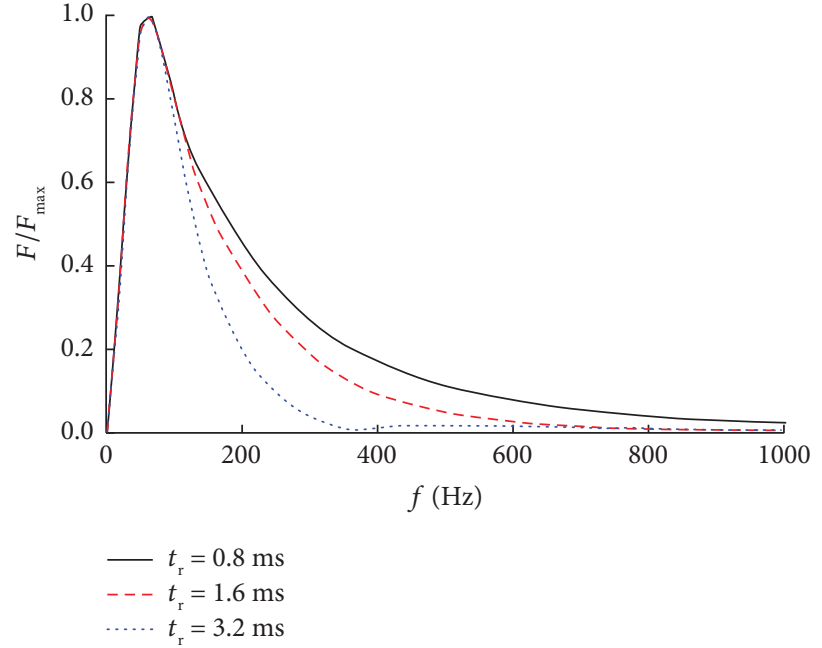

(b)

Figure 2: The effect of rise time on the frequency content: (a) in this study; (b) Yang et al. [25].

To investigate the effect of other shape functions presented in Table 1 for blasting pressure-time history on frequency content, the function proposed by Jong [23] in equation (4) is also studied by FFT analysis. The results demonstrate that the obtained frequency domain is in agreement with the previous results in Figures 3-5.

$$
P(t)=4 P_{P}\left(\exp \left(-\frac{\beta t}{\sqrt{2}}\right)-\exp (-\sqrt{2} \beta t)\right),
$$

where $P(t)$ is the shape function, $P_{p}$ is the peak blasthole pressure, $t$ is the elapsed time, and $\beta$ is the attenuation factor which can be calculated as follows:

$$
\beta=-\sqrt{2} \frac{\ln (1 / 2)}{t_{r}},
$$

where $\operatorname{tr}$ is the rise time.

Therefore, the comparison of these results with previous studies performed by Yang et al. [5, 25] demonstrates that 


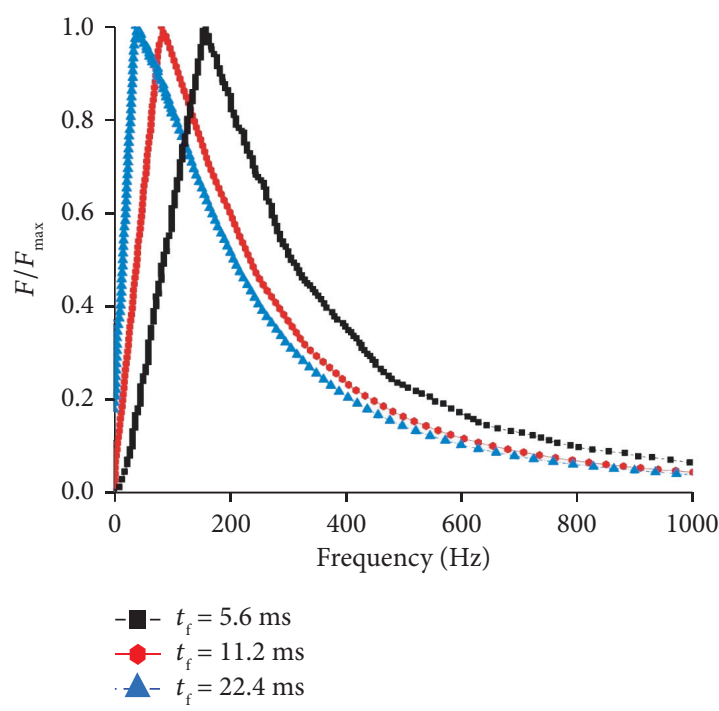

(a)

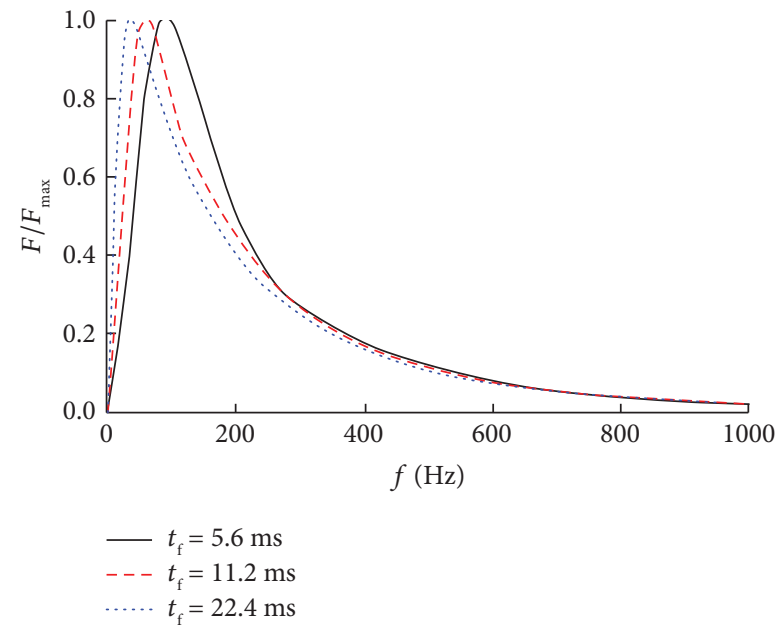

(b)

Figure 3: The effect of falling time on the frequency content: (a) in this study; (b) Yang et al. [25].

investigation of different parameters influencing blast-induced frequency content, including peak blast load pressure, rise time, and falling time by the experimental pressure-time history with its FFT analysis leads to the similar results of the study by the recorded velocity-time.

According to equation (6) proposed by Hustrolid [26], increase in the bench height and blasthole length with the same type of explosive leads to the more explosive duration time and consequently increase in the falling and rise times. Based on what is explained previously, increasing the falling and rise times decreases both dominant frequency and frequency content of the blasting wave closer to the natural frequency of the earth. This is the strong reason for increasing in vibration and damage induced by higher blasting benches into the nearby structures compared with the shorter benches.

$$
t=\frac{L}{V O D}
$$

where $t$ is explosion duration, $L$ is blasthole length, and $V O D$ is velocity of detonation.

\section{The Studied Mine: The Sangan Iron Mine}

To investigate the variation of dominant frequency in various distances from the blasthole, it is necessary to record the velocity-time histories in different monitoring points placed on a numerically simulated bench. Then, the velocity-time histories are transformed to the frequency domain by the FFT algorithm. For this purpose, one of the benches of the Sangan iron mine is modeled as a case study.

The Sangan mine is one of the most important iron mines in Iran, located about $280 \mathrm{~km}$ south-east of Mashhad. It is estimated that discovered iron ore deposits are about 1,200 billion tons and that 500,000 tons would be extracted each year. The Sangan iron ore mine includes eastern, western, and central parts and this study has been conducted

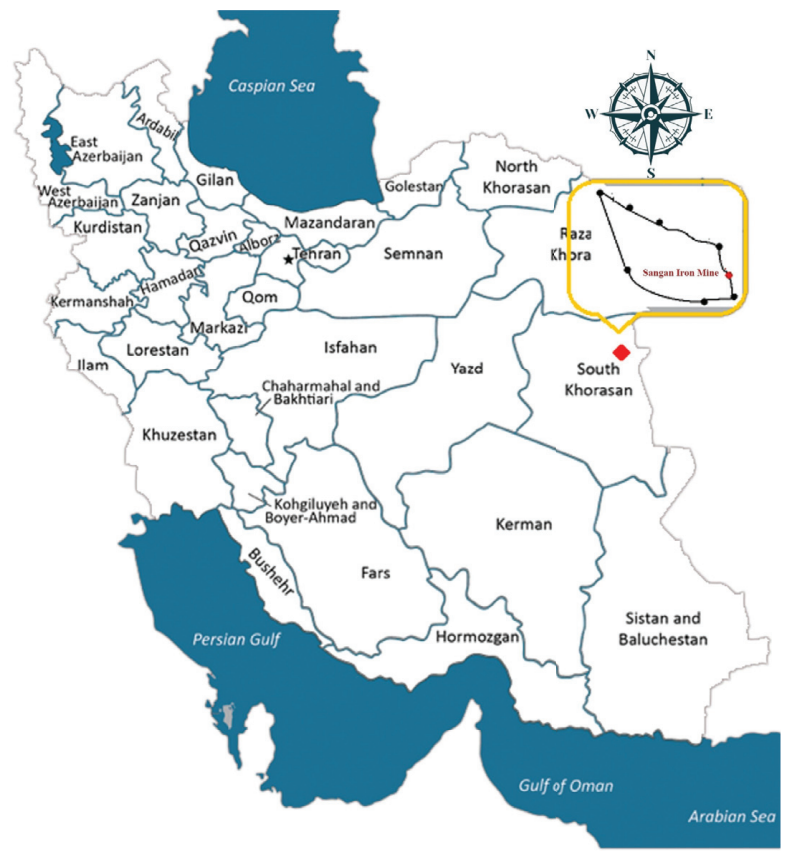

FIgURE 4: The location of Sangan iron mine (Iran).

on the central part, Cn mine. Figure 4 shows the location of the Sangan iron mine in the Iran map.

4.1. Numerical Simulation of the Studied Mine. Thanks to technological advancements, computational power has dramatically been promoted. It eases computing to perform numerical simulations of different complex processes, and blasting is not an exception. The geologic geometry, the proper boundary conditions, and the material behavior are three essential considerations that should be taken into account in any numerical simulation. The complicated blasting process needs to consider several affecting factors to 
accurately simulate the blasting process and subsequent ground vibrations [27]. In addition dynamic loading, dynamic boundary conditions, mechanical damping, and wave transmission through the model are the main effective parameters in dynamic modeling.

A comprehensive review of the different numerical methods for blasting modeling is presented by Semblat [28]. This study implemented the numerical approach to model the blasting effects. Many researchers have implemented FLAC software to conduct blasting and ground vibration simulations [29, 30]. In this study, blasting in one of the Sangan iron ore mine benches numerically simulated in the FLAC environment.

4.2. The Model Geometry and Boundary Conditions. Figure 5 shows the situation of the studied bench in the central part of the Sangan iron mine. Figure 6 shows the basic geometry of a single-blasthole simulation in one of the benches of the Sangan iron ore mine.

The simulation of single-blasthole provides a better understanding of wave propagation, attenuation, and dominant frequencies variation with distance from blasthole. Joshi et al. [31] used single-hole blasting to measure blast-induced vibration and therefore the resonance frequency of the pit wall. One of the purposes of simulating the explosion process in this mine is to investigate the dominant frequency of vibration and the effect of distance from the blasthole on its attenuation. According to Figure 6, the monitoring points, placed at a depth of 8 meters (close to the depth of the foundation of tall structures) below the surface, record the particle velocities at different distance from the explosion. The depth and diameter of the explosive hole in this numerical simulation are 13 meters and 20 centimeters, respectively. In this study, it is attempted to make the length of the model as large as possible to record the velocity-time history at different distances from the blasthole. Afterward, the velocity-time histories recorded at different distances from the blasthole are transformed into the frequency domain by FFT analysis. Figure 6 illustrates the several monitoring points at different distances from 1 to 160 meters from the blasthole.

In this study, the pressure-time history function in equation (3) proposed by Jiang and Baird [24] is utilized to simulate the dynamic loading of blasthole explosions with different types of explosives and investigate their effects. A viscous boundary condition is applied to the nonfree surfaces to prevent wave pushback into the studied area. Furthermore, mesh size plays an essential role in increasing the accuracy of the simulation results and reducing the errors relevant to passing waves from the model. Therefore, Kuhlemeyer and Lysmer [32] recommended to ensure the accuracy of a wave passing through the model; the maximum dimension of the elements should not be larger than the following:

$$
\Delta l \leq\left[\frac{\lambda}{10} \cdot \frac{\lambda}{8}\right]
$$

where $\lambda$ is the wavelength generated by the largest frequency component of the waves passing from the model.

In this study, the maximum dimension of elements was selected $20 \mathrm{~cm}$, to fulfill the essential condition for passing

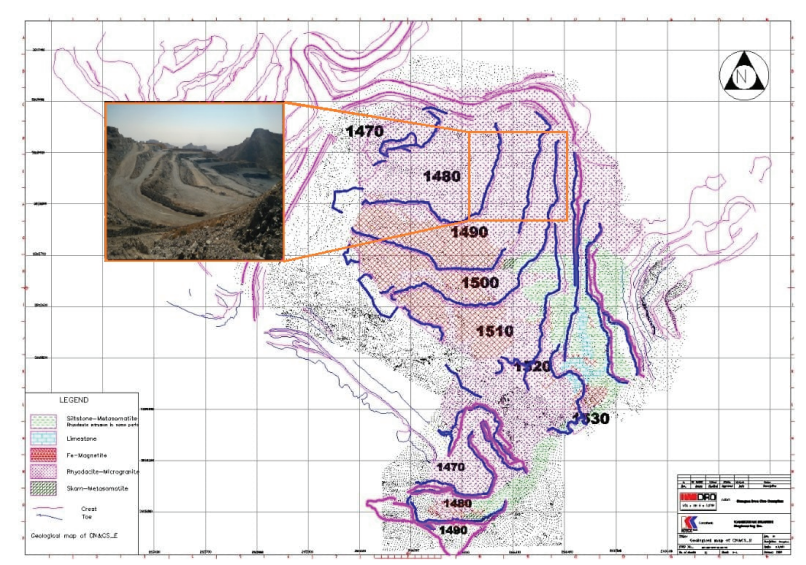

FIgURE 5: The location of the studied bench in Sangan iron mine (Iran).

the stress wave through the model. Damping parameter is one of the most imperative factors for dynamic solutions. There would be an infinity fluctuation under driving forces if damping was not considered [33]. In this study, the Rayleigh damping, including natural frequency of the model and a proportion of critical damping, is taken into account. The natural frequency of different models has been determined based on the modal analysis. The critical damping is considered to be $5 \%$ for all of the models to take into account the damping process in terms of stress and displacement.

\section{Material Properties}

Three different types of rocks, including Granite, Magnetite, and Rhyodacite from the Sangan iron ore mine, were sampled to investigate their physical and mechanical properties. Various experimental tests, including Uniaxial compressive strength, and Brazilian tests were conducted on these samples to determine the geomechanical characteristics, as shown in Figure 7. The stress-strain curves of these rock samples are shown in Figure 8.

The physical and mechanical characteristics of these three rock types of the Sangan iron mine based on the laboratory tests are summarized in Table 2.

To investigate the effects of the natural frequency of the environmental material in which the blast wave passes through on the frequency content of blast vibration, three different benches models with three different rock properties, according to Table 2, were constructed. Furthermore, the natural frequency of each model was determined based on the modal analysis. The natural frequency of the models with Granite, Rhyodacite, and Altered Magnetite materials was $12.4,9.5$, and $7.4 \mathrm{~Hz}$, respectively.

To investigate the parameters affecting the natural frequency of the model, sensitive analysis on these parameters, including Young's modulus $(E)$, Poisson ratio ( () , and material density $(\rho)$, has been conducted. As shown in Figure 9(a), a direct correlation exists between natural frequency and Young's modulus. On the other hand, Figure 9(b) demonstrates that Poisson ratio variation affects 


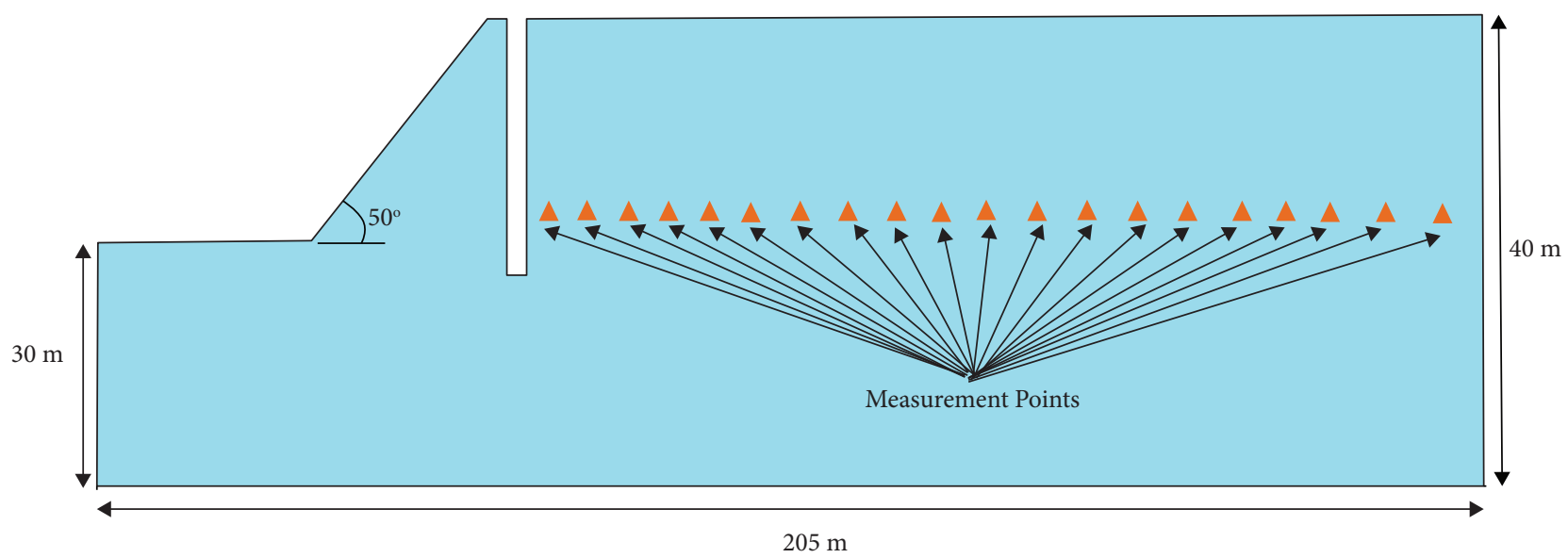

Figure 6: Basic geometry of the numerical model of the blasting process in one of the benches of the Sangan iron ore mine.

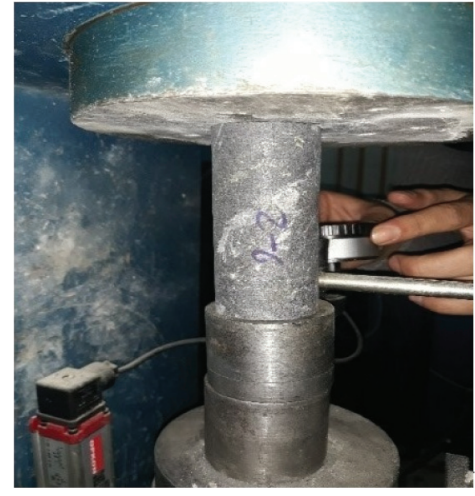

(a)

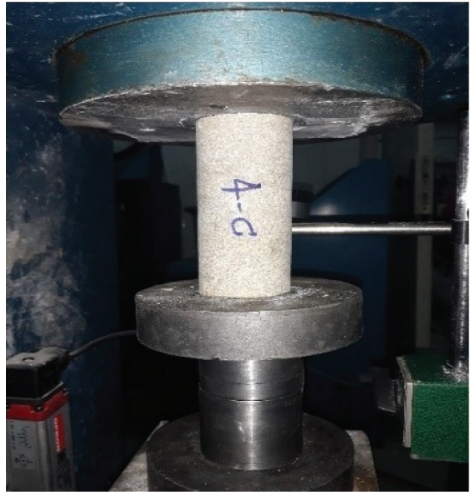

(b)

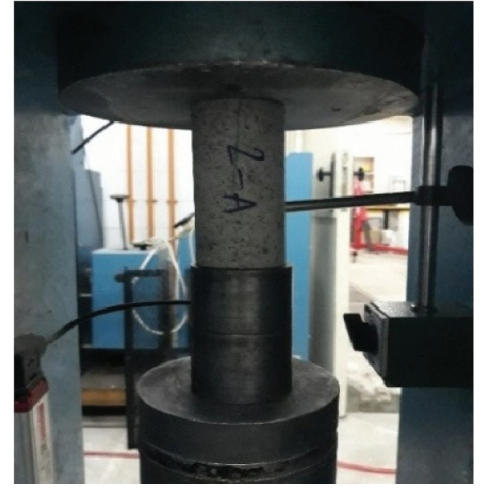

(c)

Figure 7: Three different rock specimens prepared for testing: (a) Altered Magnetite, (b) Rhyodacite, (c) Granite.

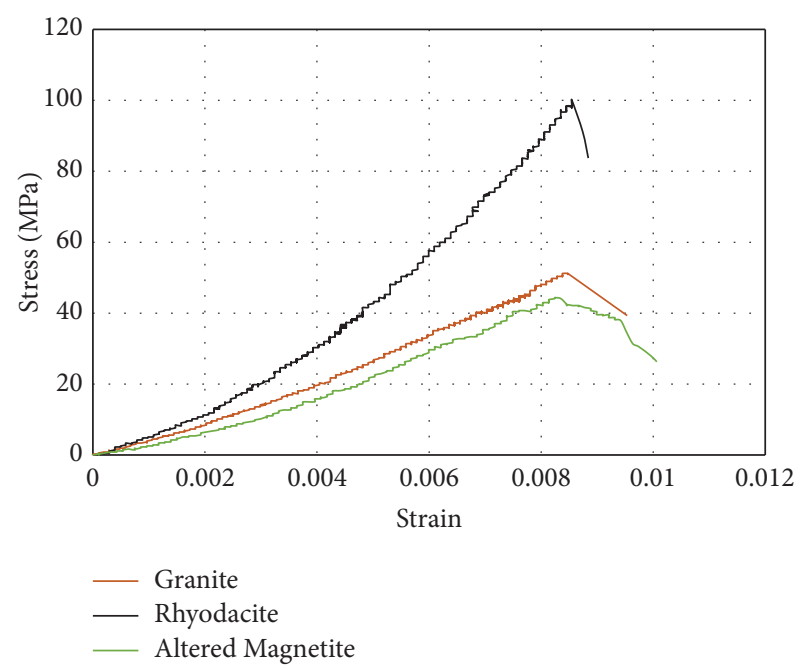

FIgURE 8: The stress-strain curves of the three rock types.

slightly natural frequency. Figure 9(c) shows a slight decrease in natural frequency due to an increment in density of the material.
To numerically analyze the vibration induced by blasthole explosion, a pressure-time history based on equation (3) is imposed to the inner boundary of the hole in the numerical model. In this study, two groups of explosives including high explosives and low explosives are implemented to investigate the effect of different dominant frequencies entering the model. Therefore, the selected explosives include ANFO, emulsion, and black powder. ANFO and emulsion are considered as high explosives according to their velocities of detonation given in Table 3, but black powder is also taken into account as a low explosive.

Figure 10 shows the pressure-time diagrams for different explosives calculated using equation (3). One crucial point of equation (3) is the calculation of blasthole pressure (PP). In this regard, the pressure due to detonation of the explosive is calculated as follows:

$$
P_{d}=\frac{\rho_{e} V O D^{2}}{4},
$$

where $P_{d}$ is detonation pressure, $V O D$ is Velocity of Detonation $(\mathrm{m} / \mathrm{s})$, and $\rho_{e}$ is density of the unreacted explosive $\left(\mathrm{kg} / \mathrm{m}^{3}\right)$. With assumption of the full coupling between 
TABLE 2: The characteristics of three rock samples of the Sangan iron ore mine.

\begin{tabular}{|c|c|c|c|c|c|c|c|}
\hline Rock type & $\begin{array}{c}\text { Young's } \\
\text { modulus (GPa) }\end{array}$ & Poisson ratio & $\begin{array}{c}\text { Uniaxial } \\
\text { compressive strength } \\
(\mathrm{MPa})\end{array}$ & Tensile strength $(\mathrm{MPa})$ & Cohesion $(\mathrm{MPa})$ & $\begin{array}{l}\text { Friction } \\
\text { angle } \\
\text { (degree) }\end{array}$ & $\begin{array}{l}\text { Density } \\
\left(\mathrm{g} / \mathrm{cm}^{3}\right)\end{array}$ \\
\hline Granite & 9 & 0.2 & 100 & 8.6 & 14.6 & 57.4 & 2.67 \\
\hline Rhyodacite & 5.2 & 0.25 & 50 & 3.15 & 6.3 & 61.8 & 2.55 \\
\hline $\begin{array}{l}\text { Altered } \\
\text { Magnetite }\end{array}$ & 4.5 & 0.27 & 43.3 & 8.53 & 9.37 & 42.2 & 3.6 \\
\hline
\end{tabular}

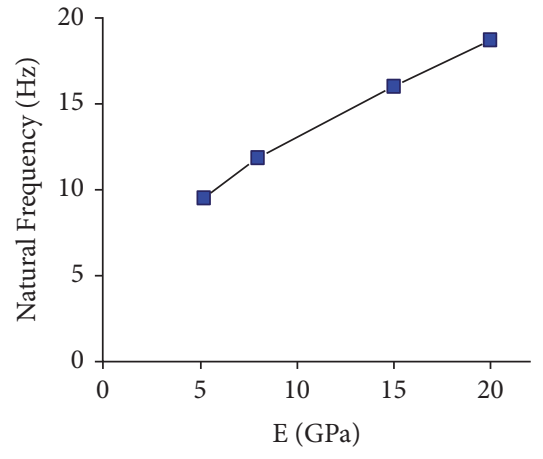

(a)

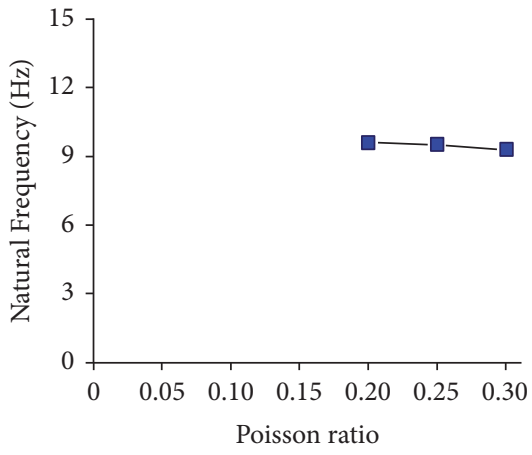

(b)

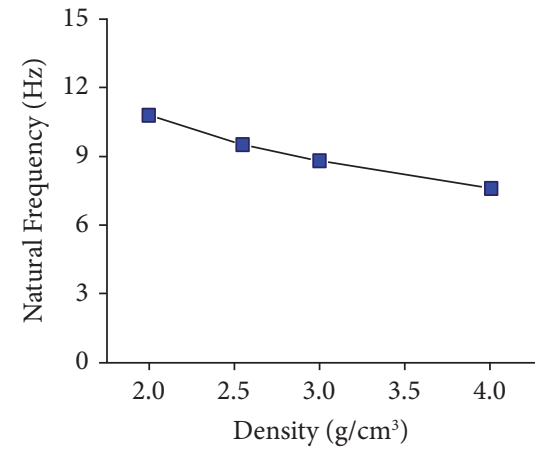

(c)

Figure 9: Natural frequency variation versus (a) deformation modulus, (b) Poisson ration, and (c) density.

TABle 3: Specifications of different explosives used in modeling [34, 35].

\begin{tabular}{lcccc}
\hline Explosive & $\begin{array}{c}\text { Velocity of detonation } \\
(\mathrm{VoD}(\mathrm{m} / \mathrm{s}))\end{array}$ & Density $\left(\rho_{e}\left(\mathrm{~kg} / \mathrm{m}^{3}\right)\right)$ & Explosion pressure $\left(P_{e}(\mathrm{GPa})\right)$ & Borehole wall pressure $\left(P_{P}(\mathrm{GPa})\right)$ \\
\hline Emulsion & 5582 & 1250 & 4.9 & 4.3 \\
ANFO & 4052 & 780 & 1.6 & 1.4 \\
Black powder & 530 & 900 & 0.0316 & 0.0275 \\
\hline
\end{tabular}

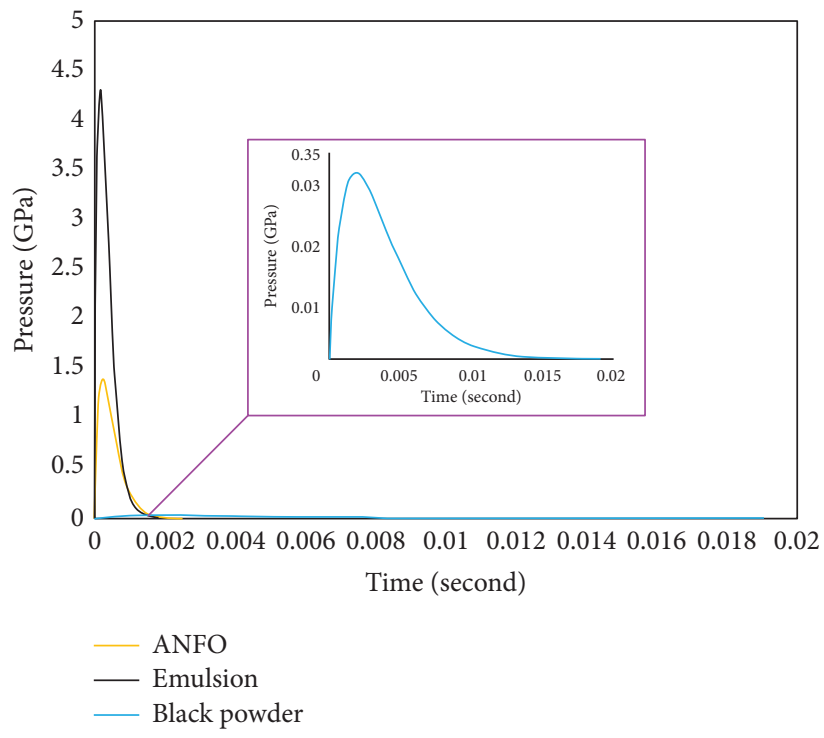

FIGURE 10: The pressure-time diagrams for different explosives used in this study using equation (3). 
explosive and blasthole wall, the explosion pressure on the borehole wall is calculated as follows:

$$
\begin{aligned}
P_{e} & =\frac{P_{d}}{2} \\
& =\frac{\rho_{e} V O D^{2}}{8},
\end{aligned}
$$

where $P_{e}$ is explosion pressure $(\mathrm{Pa})$ on the blasthole wall. The operating explosion pressure on the borehole boundary by regarding the coupling ratio of the explosive and borehole is calculated as follows [34]:

$$
P_{P}=\left(\frac{\rho_{e} V O D^{2}}{8}\right)\left(\frac{d_{c}}{d_{h}}\right)^{3},
$$

where $P p$ is borehole wall pressure $(\mathrm{Pa})$, and $\mathrm{dc}$ and $\mathrm{dh}$ are explosive and borehole diameters $(\mathrm{m})$, respectively. The characteristics of different explosives implemented in the numerical simulation and their calculated explosion pressures are summarized in Table 3.

The coupling ratio of all explosives, including ANFO, black powder, and emulsion, inside the blasthole is assumed to be $87 \%$.

\section{Results and Discussion}

According to Yang et al. [25], the surrounding structures near the blasting site are more vulnerable in higher peak particle velocities and lower vibration frequencies. Therefore, investigating the effects of different explosives and rock properties by different natural frequencies on vibration frequency is essential.

6.1. Impact of Different Explosives. In this section, the effects of the aforementioned explosive types on the vibration frequency at various distances from the blasthole are investigated. To do so, to define the characteristics of the environment, the same Rhyodacite rock properties by the natural frequency of $9.5 \mathrm{~Hz}$ were implemented for all the numerical models. According to Figure 6, the velocity-time histories for three different explosives are monitored in the $X$-direction. Then, they are transformed to the frequency domain using FFT analysis. The variation of peak particle velocity versus scaled distance and variation of dominant frequency versus distance for different explosives are shown in Figures 11 and 12.

Figures 11 and 12 show that higher strength of explosives, i.e., emulsion and ANFO, leads to higher peak particle velocity and dominant frequency at a near distance to the blasthole compared with the black powder. This proportion will stay the same in terms of peak particle velocity at a far distance away from the blasthole, but as it can be seen in Figure 12, the dominant frequency is approximately the same for all three explosives at a far distance away from the blasthole. It is because, in geomechanical environments, waves with higher dominant frequencies are damped faster at relatively short distances from the explosion source. On the other hand, low-frequency waves can propagate too

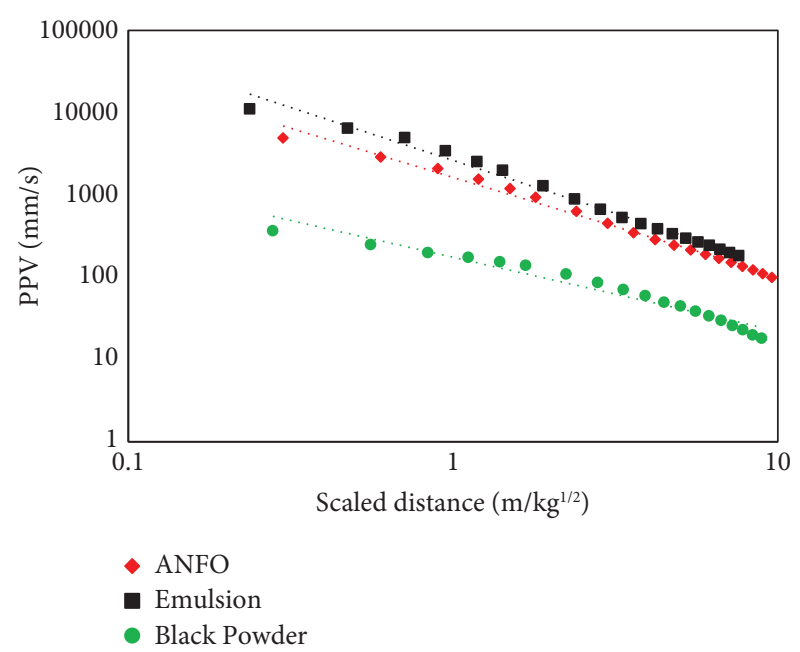

FIgURE 11: The peak particle velocity diagram versus the scaled distance for different explosives.

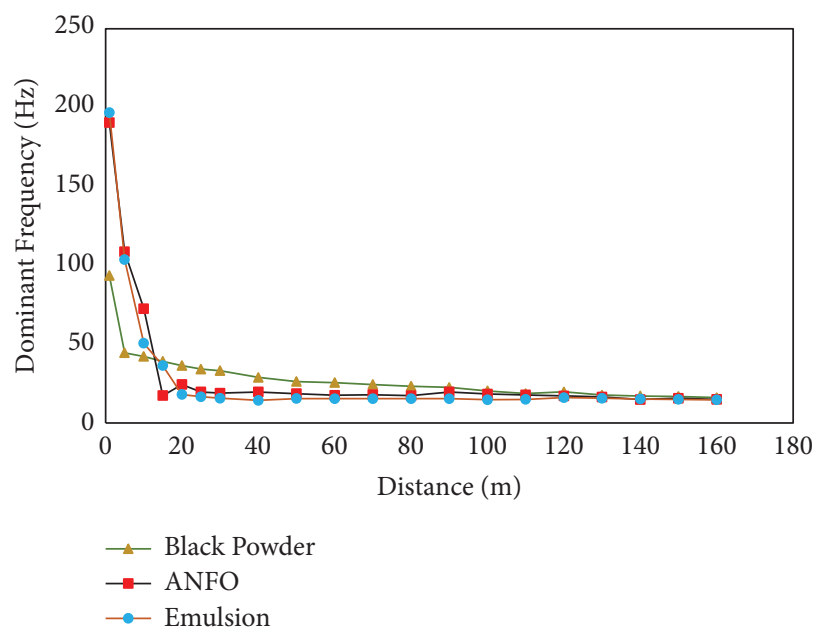

FIgURE 12: The dominant frequency diagram versus distance from the blast site for different explosives.

much greater distances from the blasthole and are the main source of damage to structures. For this reason, the earth's environment is called low-pass filters because they pass low frequencies better [36]. Therefore, as shown in Figure 12, the reduction slope of the dominant frequency of vibration made by emulsion and ANFO is higher than that of black powder because the input frequency to the model with emulsion and ANFO model is much higher than that of black powder. The general trend of dominant frequency changes versus distance is consistent with the study by Zhou et al. [6].

Regarding Section 3 and equation (6), considering VOD of different explosives and the blasthole length in Figure 6, the lowest and highest amount of explosive duration belong to emulsion and the black powder, respectively. Therefore, the lowest values of rise time and falling time and consequently the highest values of dominant frequency and frequency content are related to the emulsion while it is an opposite situation for black powder. Thus, using all the 


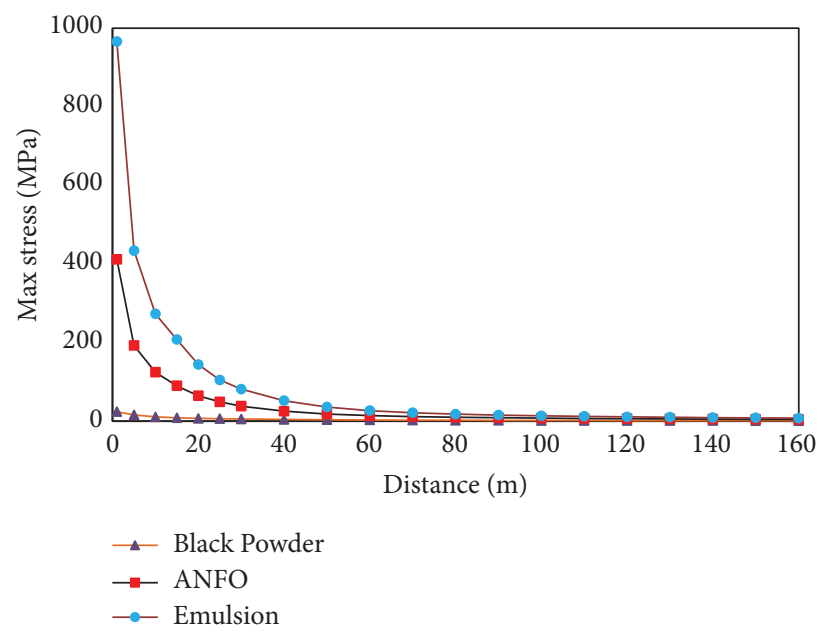

FIgURE 13: The relationship between maximum stress and distance for different types of explosives.

mentioned so far, an initial prediction of different explosives frequency is possible before blasting practice.

The relationship between maximum stress and distance for several types of explosives is shown in Figure 13. The results show that the highest level of stress is related to emulsion while black powder contains the lowest level of stress. Stresses difference also decreases by distance increment.

6.2. Impact of Natural Frequency. In this section, three numerical models with three different rock types, including Granite, Rhyodacite, and Magnetite, are constructed by the same imposed dynamic loading due to ANFO explosion. As aforementioned, the natural frequencies of the Granite, Rhyodacite, and Magnetite environments are 12.4, 9.5, and $7.4 \mathrm{~Hz}$, respectively. The variation of peak particle velocity versus scaled distance and variation of dominant frequency versus distance in monitoring points in Figure 6 for three models with different rock properties and natural frequencies are shown in Figures 14 and 15.

As can be seen in Table 4, at a one-meter distance from the blasthole, the dominant vibration frequency is the highest for the Granite environment with the highest natural frequency, while the explosive used is the same for all materials. At a distance of 160 meters away from the blasthole, the dominant vibration frequency is still the highest for the Granite rock. Furthermore, the dominant vibration frequency and its difference between materials at a one-meter distance are much greater than at a 160-meter distance from the blasthole. Therefore, the geomaterial tends to pass the vibration frequency closer to its natural frequency and attenuate the higher portion of frequency contents. If the geomaterial has a lower natural frequency, it passes the waves with lower dominant frequencies, but if the geomaterial has a higher natural frequency, it also passes the waves with higher frequencies.

As it known, the blasting stress wave with higher peak particle velocity and lower vibration frequency causes more damage to the structures surrounding the blast site [25], and

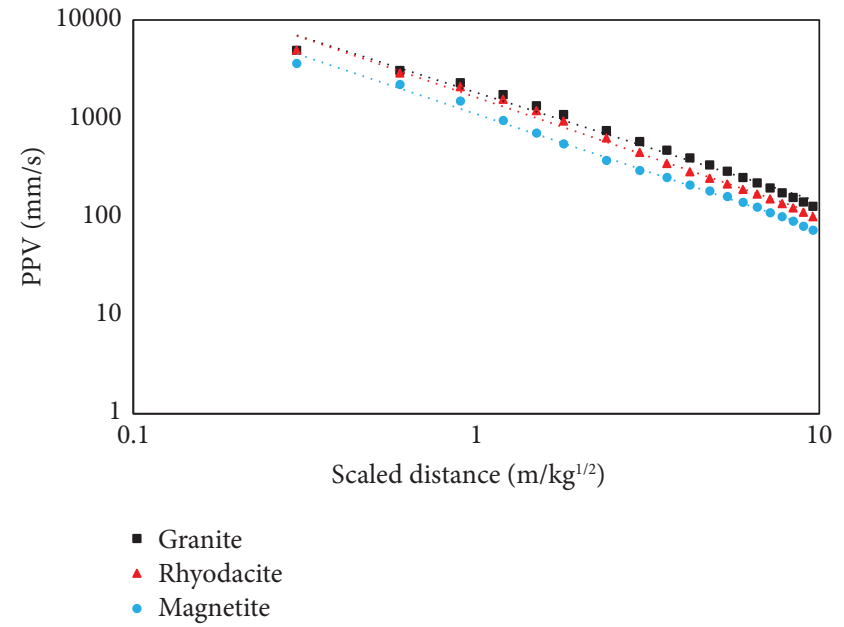

FIGURE 14: The peak particle velocity versus the scaled distance for three materials with different natural frequencies.

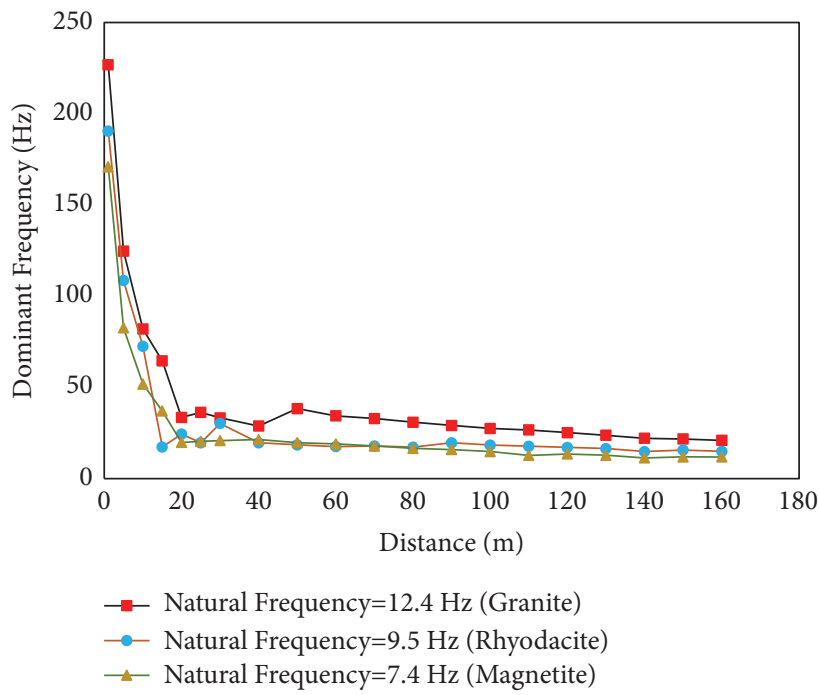

FIGURE 15: Dominant frequency diagram versus distance for different natural frequencies. 
TABLE 4: Dominant vibration frequency variation at different distances from the blasthole with different natural frequencies.

\begin{tabular}{lccccc}
\hline $\begin{array}{l}\text { Geomaterial } \\
\text { environment }\end{array}$ & $\begin{array}{c}\text { Natural ground } \\
\text { frequency }(\mathrm{Hz})\end{array}$ & $\begin{array}{c}\text { Distance from } \\
\text { blasthole }(\mathrm{m})\end{array}$ & $\begin{array}{c}\text { The dominant frequency } \\
\text { of vibration }(\mathrm{Hz})\end{array}$ & $\begin{array}{c}\text { Distance from } \\
\text { blasthole }(\mathrm{m})\end{array}$ & $\begin{array}{c}\text { The dominant frequency } \\
\text { of vibration }(\mathrm{Hz})\end{array}$ \\
\hline $\begin{array}{l}\text { Magnetite } \\
\text { Rhyodacite }\end{array}$ & 7.4 & 1 & 170.9 & 160 & 11.86 \\
Granite & 9.5 & 1 & 190.5 & 160 & 14.93 \\
\hline
\end{tabular}

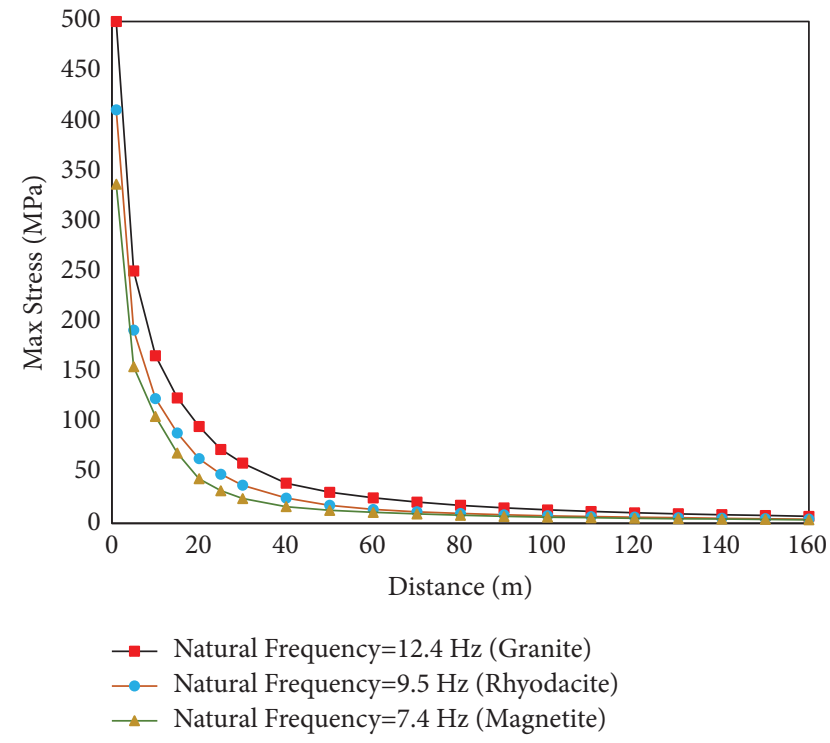

FIGURE 16: The relationship between maximum stress and distance for materials containing different natural frequencies.

it can be seen in Figures 14 and 15 that peak particle velocity and dominant vibration frequency are higher in the geomaterial with higher natural frequency and vice versa. Therefore, in geomaterials with a lower natural frequency, damage induced by vibration frequency should be considered.

The relationship between maximum stress and materials containing different natural frequencies is also shown in Figure 16. As it can be seen there is direct correlation between induced maximum stress, due to blast practice, and natural frequency of materials. However, the maximum stresses difference will gradually fade by distance increasing.

\section{Conclusion}

Due to the importance of the adverse effects of the explosion, especially on surrounding structures near the explosion site, the study of the blast-induced frequency content is of particular importance, so in this study, the parameters affecting the frequency content and also dominant frequencydependent attenuation versus distance have been studied.

The results of this study and its comparison with previous studies demonstrate that investigation of different parameters influencing blast-induced frequency content, including peak blast load pressure, rise time, and falling time by the FFT analysis of the experimental pressure-time history, leads to similar results of the study by velocity-time recorded data of an infield blasting. The results also show a lower dominant frequency and frequency content derivation, by considering a higher mine bench, which increases the adverse effects on nearby surrounding structures.

The study results on dominant frequency attenuation in geomaterial with different natural frequencies and various implemented explosives show a rapid drop of dominant frequency to half the original value at a near distance. Therefore, the geomaterial tends to pass the vibration frequency close to its natural frequency and attenuate the high frequency of vibration. It is also evident that the more the power of explosives, the higher the peak particle velocity at both near and far distances away from blasthole.

The generated dominant frequencies of both high and low explosives show thep psame behavior far distance away from the blasthole in a specific type of geoenvironment, while the environments containing higher natural frequencies cause a higher dominant frequency of any type of explosives.

In the bottom line, the higher natural frequency causes a higher maximum particle velocity and higher vibration frequencies. Therefore, monitoring on low adverse vibration frequencies generated in low natural frequency contained geoenvironments should be considered.

\section{Data Availability}

No data were used to support this study.

\section{Conflicts of Interest}

The authors declare that they have no conflicts of interest.

\section{References}

[1] T. N. Hagan, "Rock breakage by explosives," in Gasdynamics of Explosions and Reactive Systems, pp. 329-340, Elsevier, Hoboken, NJ, USA, 1980.

[2] R. Trivedi, T. N. Singh, and A. K. Raina, "Prediction of blastinduced flyrock in Indian limestone mines using neural networks," Journal of Rock Mechanics and Geotechnical Engineering, vol. 6, no. 5, pp. 447-454, 2014.

[3] S. A. Taqieddin, "Ground vibration levels: prediction and parameters," Mining Science and Technology, vol. 3, no. 2, pp. 111-115, 1986.

[4] H. K. Kutter and C. Fairhurst, "On the fracture process in blasting," International Journal of Rock Mechanics and Mining Sciences \& Geomechanics Abstracts, vol. 8, no. 3, pp. 181-202, 1971.

[5] J. Yang, J. Cai, C. Yao, P. Li, Q. Jiang, and C. Zhou, "Comparative study of tunnel blast-induced vibration on tunnel surfaces and inside surrounding rock," Rock Mechanics and Rock Engineering, vol. 52, no. 11, pp. 4747-4761, 2019.

[6] J. Zhou, W. Lu, P. Yan, M. Chen, and G. Wang, "Frequencydependent attenuation of blasting vibration waves," Rock 
Mechanics and Rock Engineering, vol. 49, no. 10, pp. 40614072, 2016.

[7] M. Khandelwal and T. N. Singh, "Prediction of blast induced ground vibrations and frequency in opencast mine: a neural network approach," Journal of Sound and Vibration, vol. 289, no. 4-5, pp. 711-725, 2006.

[8] M. Monjezi, M. Ghafurikalajahi, and A. Bahrami, "Prediction of blast-induced ground vibration using artificial neural networks," Tunnelling and Underground Space Technology, vol. 26, no. 1, pp. 46-50, 2011.

[9] C. Wu and H. Hao, "Numerical study of characteristics of underground blast induced surface ground motion and their effect on above-ground structures. Part I. Ground motion characteristics," Soil Dynamics and Earthquake Engineering, vol. 25, no. 1, pp. 27-38, 2005.

[10] C. Caylak, A. Kocaslan, K. Gorgulu, A. Buyuksarac, and E. Arpaz, "Importance of ground properties in the relationship of ground vibration-structural hazard and land application," Journal of Applied Geophysics, vol. 104, pp. 6-16, 2014.

[11] P. K. Singh, M. P. Roy, R. K. Paswan, R. K. Dubey, and C. Drebenstedt, "Blast vibration effects in an underground mine caused by open-pit mining," International Journal of Rock Mechanics and Mining Sciences, vol. 80, pp. 79-88, 2015.

[12] G. R. Tripathy, R. R. Shirke, and M. D. Kudale, "Safety of engineered structures against blast vibrations: a case study," Journal of Rock Mechanics and Geotechnical Engineering, vol. 8, no. 2, pp. 248-255, 2016.

[13] A. Rashiddel, M. Kharghani, D. Dias, and M. Hajihassani, "Numerical study of the segmental tunnel lining behavior under a surface explosion - i," Computers and Geotechnics, vol. 128, Article ID 103822, 2020.

[14] M. Bahaaddini, "Effect of boundary condition on the shear behaviour of rock joints in the direct shear test," Rock Mechanics and Rock Engineering, vol. 50, no. 5, pp. 1141-1155, 2017.

[15] H. R. Mohammadi, H. Mansouri, M. Bahaaddini, and H. Jalalifar, "Investigation into the effect of fault properties on wave transmission," International Journal for Numerical and Analytical Methods in Geomechanics, vol. 41, no. 17, pp. 1741-1757, 2017.

[16] M. Lak, M. Fatehi Marji, A. Yarahmadi Bafghi, and A. Abdollahipour, "A coupled finite difference-boundary element method for modeling the propagation of explosioninduced radial cracks around a wellbore," Journal of Natural Gas Science and Engineering, vol. 64, pp. 41-51, 2019.

[17] M. Lak, M. Fatehi Marji, A. Yarahamdi Bafghi, and A. Abdollahipour, "Discrete element modeling of explosioninduced fracture extension in jointed rock masses," Journal Min. Environ., 2018.

[18] S. Esen, I. Onederra, and H. A. Bilgin, "Modelling the size of the crushed zone around a blasthole," International Journal of Rock Mechanics and Mining Sciences, vol. 40, no. 4, pp. $485-495,2003$.

[19] J. A. Sharpe, "The production OF elastic waves by explosion pressures. I. theory and empirical field observations," Geophysics, vol. 7, no. 2, pp. 144-154, 1942.

[20] W. I. Duvall, "Strain-wave shapes in rock near explosions," Geophysics, vol. 18, no. 2, pp. 310-323, 1953.

[21] J. Jiang, D. P. Blair, and G. R. Baird, "Dynamic response of an elastic and viscoelastic full-space to a spherical source," International Journal for Numerical and Analytical Methods in Geomechanics, vol. 19, no. 3, pp. 181-193, 1995.

[22] C. Jommi and A. Pandolfi, "Vibrations induced by blasting in rock: a numerical approach," Rivista Italiana di Geotecnica, vol. 20, pp. 77-94, 2008.
[23] Y. Jong, "Numerical modeling of the circular-cut using particle flaw code," in Proceedings of the 1st Annular Conference of Explosives and Blasting Technique, Orlando, FL, USA, February 2005.

[24] D. J. Jiang and G. R. Baird, "Surface vibrations due to a buried explosive source," in Proceedings of the International Symposium on Rock Fragmentation by Blasting, no. 4, Vienna, Austria, July 1993.

[25] J. Yang, W. Lu, Q. Jiang, C. Yao, S. Jiang, and L. Tian, “A study on the vibration frequency of blasting excavation in highly stressed rock masses," Rock Mechanics and Rock Engineering, vol. 49, no. 7, pp. 2825-2843, 2016.

[26] W. Hustrolid, Blasting Principles for Open Pit Mining, AA Balkema, Amsterdam, Netherlands, 1999.

[27] A. Bobet, A. Fakhimi, S. Johnson, J. Morris, F. Tonon, and M. R. Yeung, "Numerical models in discontinuous media: review of advances for rock mechanics applications," Journal of Geotechnical and Geoenvironmental Engineering, vol. 135, no. 11, pp. 1547-1561, 2009.

[28] J. F. Semblat, "Modeling seismic wave propagation and amplification in 1D/2D/3D linear and nonlinear unbounded media," International Journal of Geomechanics, vol. 11, no. 6, pp. 440-448, 2011.

[29] I. A. Onederra, J. K. Furtney, E. Sellers, and S. Iverson, "Modelling blast induced damage from a fully coupled explosive charge," International Journal of Rock Mechanics and Mining Sciences, vol. 58, pp. 73-84, 2013.

[30] R. Resende, L. Lamas, J. Lemos, and R. Calçada, "Stress wave propagation test and numerical modelling of an underground complex," International Journal of Rock Mechanics and Mining Sciences, vol. 72, pp. 26-36, 2014.

[31] V. P. Joshi, A. Tripathi, R. Konidina, and V. Misra, "A case study on wall stability at Rampura Agucha Mine using electronic blasting systems," Rock Fragmentation by Blasting, pp. 767-772, 2012.

[32] R. L. Kuhlemeyer and J. Lysmer, "Finite element method accuracy for wave propagation problems," Journal of the Soil Mechanics and Foundations Division, vol. 99, no. 5, pp. 421427, 1973.

[33] A. Mortazavi, Introduction to Rock Dynamics, Amirkabir University of Technology, Tehran, Iran, 2016.

[34] O. Yilmaz and T. Unlu, "Three dimensional numerical rock damage analysis under blasting load," Tunnelling and Underground Space Technology, vol. 38, pp. 266-278, 2013.

[35] M. Leidig, J. L. Bonner, T. Rath, and D. Murray, "Quantification of ground vibration differences from well-confined single-hole explosions with variable velocity of detonation," International Journal of Rock Mechanics and Mining Sciences, vol. 47, no. 1, pp. 42-49, 2010.

[36] T. N. Singh, L. K. Dontha, and V. Bhardwaj, "Study into blast vibration and frequency using ANFIS and MVRA," Mining Technology, vol. 117, no. 3, pp. 116-121, 2008. 